\title{
The Impact of Herding on the Expected Return in the Egyptian Stock Exchange
}

\author{
Mostafa Hussein Abd Alla \\ Sadat Academy for Management Sciences \\ Department of Business Administration \\ Cairo, Egypt \\ Email: m_haa60@yahoo.com

\section{Mahmoud Sobh} \\ Ain Shams University \\ Faculty of Commerce \\ Cairo, Egypt
}

\begin{abstract}
This paper examines the impact of herding behaviour on the expected return in the Egyptian Stock Exchange by adding an additional risk factor reflecting herding behaviour to the capital asset pricing model. The study used monthly excess stock returns of 50 stocks listed on the Egyptian Stock Exchange from January 2014 to December 2018. The results do not support the capital asset pricing model before and after adding the herding behaviour factor, therefore there is no effect of herding behaviour on the expected return.
\end{abstract}

Keywords: CAPM model, herding behaviour

JEL codes: G12, G41

\section{Introduction}

Efficient Market Hypothesis (EMH) and behavioral finance have been the cause of much controversy for decades, where one of them defending markets efficiency and the other opposing it. The EMH hypothesis assumes investor rationality and stock prices quickly adapt to new information and reflect all available information. In contrast, behavioral finance focuses on studying the impact of psychology on the behavior of investors or financial analysts and suggests that markets are unreasonable, where investors make unreasonable decisions, which may lead to inaccurate asset pricing.

The field of financial modeling is one of the most important fields in the theory of modern finance, which examines the relationship between return and risk; there have been many developments in this field since the introduction of the portfolio theory by Harry Markowitz (1952). This led to the development of many models to examine the relationship between return and risk. The most important of these models is the Capital Asset Pricing Model (CAPM), which presented by Sharpe (1964) and Lintner (1965) and developed on the basis of portfolio theory by Harry 
Markowitz (1952), is the most substantial and popular model in the pricing of assets. The CAPM model is considered the first capital asset pricing model to explain the relationship between the return of any asset and the risks arising from the investment in these assets. The model indicates that there is only one factor which explains the return of any asset, which is the systematic risk, which means the market related risk of that asset. Therefore, the CAPM model is also known as single factor model.

However, there are several studies that have criticized the CAPM model in an attempt to find a better model for explaining the relationship between return and risk, such as the CAPM with Non-Marketable Human Capital for Mayers (1972), the Black Zero-beta CAPM model (1972), The Intertemporal CAPM for Merton (1973), International Asset Pricing Model for Solnik (1974), Partial variance model presented by Hogan \& Warren (1974), Bawa \& Lindenberg (1977), Arbitrage Pricing Model for Ross (1976), production-based asset pricing model for Lucas (1978), Brock (1979), three Factor Asset Pricing Model presented by Fama \& French (1993), And Liquidity Based CAPM for Acharya and Pedersen (2005), and other different pricing models.

In this study, we will study the field of behavioral finance as one of the most important fields of the modern finance, where investor behavior has become one of the most important considerations to take into account when talking about the finance and investment, Because of its great influence on the pricing of capital assets. Consequently, we will identify the impact of one of the most important factors of behavioral finance is the herding behavior on the expected return in the Egyptian Stock Exchange (EGX) by adding an additional risk factor reflecting herding behaviour $\left(h_{m t}\right)$ to the the CAPM model, where the CAPM model will be tested in its original form and re-tested after adding the additional risk factor from January 2014 to December 2018, in order to know the effect of herding on the expected return in the Egyptian stock exchange.

\section{Capital Asset Pricing Model}

\subsection{Theoretical Literature}

The CAPM developed by Sharpe (1964) and Lintner (1965), is based on the work of Harry Markowitz (1959) who developed the "mean-variance model". The CAPM model pointed out that there is a positive linear relationship between the expected risk of the asset and the expected rate of return. The only measure of risks is the systematic risk, which is measured through beta. According to the CAPM, the relationship between the expected return on the stock and its systematic risk measured by beta is positive. The model assumes that there is an equilibrium relationship between risk and return, which helps in identifying the underpriced and overpriced assets. This equilibrium relationship is known as the security 
market line (SML). The SML explains the relationship between the return on asset and beta of asset.

The CAPM equation according to Sharpe and Lintner assumption is expressed as follows:

$$
E\left(R_{i t}\right)=R_{f}+\beta\left(R_{m t}-R_{f}\right)
$$

where $E\left(R_{i t}\right)$ is the expected return on asset $i$, and $\beta$ is the market beta that measures the sensitivity of the return on asset to variation in the return of market portfolio. $R_{f}$ is the risk free rate, and $R_{m t}$ is the market return. According to the sharpe-Lintner CAPM equation, the expected return equal to the risk free rate of return $R_{f}$ plus the market risk premium which consists of the expected market return $R_{m t}$ minus the risk free rate times.

\subsection{Empirical Literature}

Strong and Xu (1997) used tow-pass regressions method to test the relationship between the systematic risk coefficient (beta) and the stock returns listed on the London Stock Exchange during the period 1960-1992. The study found that there is a positive relationship between the beta and the expected rate of return, if beta is considered the only variable affecting the expected rate of return. However, beta became insignificant when adding leverage and the book-to-market ratio (B/M) to the relation, where the results showed that the leverage and the book-to-market ratio were statistically significant.

Clare et al. (1998) examined the relationship between the systematic risk factor and the expected rate of return. The study used the monthly stock returns of 100 companies listed on the London Stock Exchange between January 1980 and December 1993. The study concluded that the systematic risk factor is statistically significant and have a large explanatory power for the expected return on the London Stock Exchange.

Theriou et al (2005) examined the ability of the CAPM model to explain the relationship between the cross-section of average returns and beta for a sample of all non-financial companies listed on the Athens Stock Exchange, they used monthly returns of stocks from July 1993 to June 2001. The study found that beta is not able to explain the cross-section of average returns.

Choudhary \& Choudary (2010) examined the CAPM model using monthly return of a sample of 278 companies listed on the BSE 500 Index on the Bombay Stock Exchange from January 1996 to December 2009. The study divided the sample into 20 portfolios and then arranged them based on beta values. The results showed that that it does not support the basic conclusion of the theory that the higher the 
systematic beta risk factor the higher the return on investment, where the results showed that the portfolio that achieved the highest value of the beta factor ( $\beta=$ 1.773 ) achieved an average monthly return equal to $23 \%$, While the portfolio with the lowest beta coefficient ( $\beta=0.7795$ ) achieved an average monthly return equal to $26 \%$, therefore the CAMP is unable to explain the expected return in the Bombay Stock Exchange.

\section{Herding Behaviour}

\subsection{Theoretical Literature}

At the end of the 19th century, Gustave Le Bon (1895), the psychologist and sociologist, studied the psychology of the crowd and pointed out that when people became members in crowds, they're irresponsible and contagion. The absence of responsibility means that when the person is inside the crowds, he has a state of absence of responsibility that controls her behaviour, and he does actions that he would not otherwise have chosen if he was not in the crowd. Second, contagion means that when the person is inside the crowds, he ignores his personal beliefs and adapts to the beliefs of the people in the crowd. The impact of group opinions on the behaviour of person is very strong in the case of the absence of uncertainty and has sufficient information (Gavriilidis, 2013). Bikhchandani and Sharma (2001) defined herd behaviour as intentional or inadvertent duplication of the behaviour of other investors.

The classical theory supports the independence of investor decisions and assumes the rational behaviour for investors. The herding behavior is considered one of the most important factors of behavioral finance. Herd behaviour occurs when investors decide to imitate each other's decisions in the market rather than following their own information. Thus the return on individual stocks will move in the same direction as the return on market portfolio. That makes returns on individual stocks very close to the return on market portfolio (Hwang and Salmon, 2004). The investors believe that it's reasonable to imitate each other's, if that will allow them to benefit from information experiences of others, perhaps investors believe that their information is inefficient, or sees others better informed (Devenow and Welch, 1996)

There is another type of herding called spurious herding, where there is similarity in the behaviour of investors because of the similarity of reactions to the signals observed in the market in general, and not in the imitation of others. This similarity in the behaviour does not necessarily result from irrational behaviour. For example, if there is a drop in the interest rate on deposits, investors may be turn to the stock market for higher returns. (Bikhchandani and Sharma, 2001) 


\subsection{Empirical Literature}

Many studies have measured herd behaviour in the financial markets. Christie \& Huang (1995) proposed the Cross Sectional Standard Deviation of Returns (CSSD) as a measure of dispersion to measure the herd behaviour, where they measured the herd behaviour in the market by observing the relationship between market returns and cross-sectional standard deviation of asset returns. Herd behaviour means that the return on individual stocks is closing to the return on the market. They assumed that the investor disregards his beliefs when making the investment decision. The study applied the method of dispersion of return on the daily and monthly data of NYSE and AMEX from 1962 to 1988 . This method failed to detect herd in the market.

Chang et al. (2000) developed the work of Christie and Huang (1995), they developed a method based on the Cross Sectional Absolute Deviation of return (CSAD) in a nonlinear regression to examine the relation between the level of stock return dispersions and the market return. The study measured herd behaviour in some international stock markets. The study concluded that herding behaviour was not found in the developed markets such as Unites States and Hong Kong, but the results indicated a presence of herd behaviour in the emerging markets such as South Korea and Taiwan.

Hwang and Salmon (2004) developed a different approach in their study on the Unites States and South Korean markets based on the Cross-Sectional Standard Deviation of the beta to test herding in United Kingdom, Unites States, and South Korean markets. In case of irrational behaviour of investors, their evaluation of the relationship between return and risk is incorrect. Thus, in the case of the existence of herd behaviour among investors in the market, the return on the investments moves in the same direction as the market portfolio return, therefore CAPM-betas will swerve from its equilibrium estimate. They found herding in the normal market conditions rather than the market stress.

Ouarda et al. (2012) tested the herd behavior for a sample of 174 stocks listed on the STOXX Europe 600 index, using monthly data from January 1998 to December 2010. The study divided the sample into 10 different sectors to study herd behavior at the sectoral level. The study also used the Chang et al. (2000) model to measure herd behavior. The study found that the majority of the sectors identified confirm the presence of herd behavior except for the consumer goods sector.

Elkhaldi and Benabdelfatteh (2014) examined herding in the Tunisian Stock Exchange. They used daily data for a sample of 10 stocks from June 2002 to May 2013; the study also used Hwang and Salmon (2004) method to measure herd 
behavior. They found evidence confirm the presence of herd behavior among investors in the Tunisian stock market.

Messis and Zapranis (2014) examined the presence of herd behaviour in the Athens Stock Exchange for a sample of 41 stocks from February 1995 to April 2010. The study also used Hwang and Salmon (2004) method to measure herd behavior. They found that the herd behaviour was found during different periods of the study. They considered herd behaviour as an additional risk factor.

Vieira and Pereira (2015) investigated the presence of the herd behaviour in the Portuguese stock market, for a sample of 20 stocks from January 2003 to December 2011. The study used Chang et al. (2000) and Christie and Huang (1995) to measure herd behavior. The study found that there is no evidence of herd behaviour in the Portuguese stock market, which suggests some evidence of the efficiency hypothesis of the Portuguese market.

Javaira and Hassan (2015) examined the herd behaviour in the Pakistani stock market. The study used Christie and Huang (1995) and Chang et al. (2000) to measure herd. The study used daily and monthly closing prices of the KSE-100 index from 2002 to 2007. The study found that there is no evidence of herd behaviour in the Pakistani stock market. The study attributed the absence of herd behaviour to the asymmetry in market returns. However, in March 2005, during the liquidity crisis in the Pakistani stock market, the presence of herd behaviour was observed due to asymmetry of information among investors.

Lee et al. (2015) investigated the presence of the herd behaviour in the Taiwan stock market, the study also aimed to test the relationship between different market conditions (return on the market portfolio, trading volume, interest rate, market index volatility, return on the S\&P500 index), and herd behavior. The study used the linear model based on the concept of (CSSD) used by Christie and Huang (1995), and the non-linear model based on (CSAD) proposed by Chang et al. (2000) to study herd behavior among investors from January 4, 2000 to December 28,2012 . The study found the herd behavior among investors in the Taiwan stock market based on the non-linear model proposed by Chang et al. (2000), while the cross sectional standard deviation (CSSD) used by Christie and Huang (1995) failed to demonstrate the herd behaviour in the Taiwan stock market. The study also found that there was a positive correlation between herd behaviour and the return on the S \& P500 index. There is also a negative relationship between the herd behaviour and the interest rate, where the herd behaviour is greater in the case of lower interest rate than the rise in interest rate, which indicates the desire of investors to invest in stocks in the case of low interest rate. 
Özsu (2015) tested the herd behaviour in the Istanbul Stock Exchange, using daily returns from January 14, 1988 to December 31, 2014, the sample of the study ranged from 47 companies at the beginning of 1988 to 441 at the end of 2014 . The study used Christie and Huang (1995) methodology to measured herd behaviour. To confirm the results, the study re-tested the herd behaviour by using the Hwang and Salmon model (2004). The study found that there was no herd behaviour in Istanbul Stock Exchange in cases of rise or fall in the market, in the case of using the Christie and Huang (1995) model. When using the Hwang and Salmon (2004) model, the study found the presence of herd behaviour among investors, where it was noted that investors follow the direction of the market, and the study found that investors imitate others under normal market conditions more than the turbulent market conditions.

Metwally et al (2016) examined herd behaviour in the Egyptian stock market in the case of uptrend and down trend of the market. The study used daily closing prices, market returns from January 2007 to December 2012. They used the Christie and Huang (1995) model, and Chang et al. (2000) model to measured herd behaviour. They found evidence confirm the presence of herd behavior in the Egyptian stock market, where the returns of individual stocks have a low dispersion from market returns during the study period. They also found that the herd behaviour is stronger during declining market returns (down trend), which means that investors in Egypt follow the performance of the market and ignore the individual characteristics of stocks, while no evidence was observed on herd behaviour during the volatility High market. The study also found that there is no evidence of herd behaviour among investors in the case of the uptrend.

\section{Data and Methodology}

\subsection{Data}

In this study, we use daily and monthly returns for individual stocks and EGX100 index for a sample of firms listed on the EGX from January 2014 to December 2018 to test the CAPM model in its original form and re-tested after adding the herding behaviour as additional risk factor to the relation between risk and return in the CAPM model, in order to know the effect of herding behaviour on the expected return in the Egyptian Stock Exchange. EGX100 measures the performance of the 100 active companies in the EGX. These companies including both the 30 companies of EGX 30 Index and the 70 companies of EGX 70 Index. returns on EGX100 index was used as a proxy for the market portfolio returns; monthly returns on the Postal Savings was used as a proxy for the risk free rate. The monthly beta values for each stock in the sample was calculated to be used in measuring herd behavior. We follow a set of criteria for selecting sample stocks, as follows: 
- Stocks should only be listed on EGX100 index.

- The trading currency of the stock is the Egyptian pound.

- Eliminate Stocks of banks and financial institutions.

- Stock returns should be available for 60 continuous months.

By applying these standards, we got a sample of 50 stocks listed on EGX100 index in the Egyptian Stock Exchange.

\subsection{CAPM Model}

We tested the CAPM in the two stages of regression. The time series regression is the first stage of regression, where beta of each stock is calculated by regressing the monthly excess returns of stock on the monthly excess return of the market portfolio. It calculated by the following equation:

$$
R_{i t}-R_{f}=\alpha+\beta_{m t}\left(R_{m t}-R_{f}\right)+\varepsilon_{i t}
$$

where Rit and Rmt is the rate of return on asset $\mathrm{i}$ and market portfolio at time $\mathrm{t}$, respectively. $R f$ is the risk-free rate at time $t, \beta m t$ is the beta of stock $i$, sit is the error term, and $\alpha$ is the intercept.

Beta $(\beta)$ of each stock is calculated and used in the second stage of regression. The second stage of regression is the cross sectional regression. Where the average excess return of stocks is regressed on beta of stocks. It calculated by the following equation:

$$
R_{I}=Y_{0}+Y_{1} \beta_{m t}+\varepsilon_{i t}
$$

where $R_{I}$ is the average excess return of stocks, $Y_{t}$ is the average risk premium, $\beta_{m t}$ is the estimated beta of the stock, $\varepsilon_{i t}$ is the error term and $Y_{0}$ is the intercept term.

\subsection{Herding Behavior Measurement}

At the fist, we obtained 60 monthly beta estimates for each stock. We estimated beta coefficients using the OLS method, based on daily observations of each month, as follows:

$$
r_{i t d}=\alpha_{i t}^{b}+\beta_{i m t}^{b} r_{m t d}+\varepsilon_{i t d}
$$

where $r_{i t d}$ is the excess returns; $r_{m t d}$ is the excess market returns and $(t d)$ refers to the daily data for month $\mathrm{t}$.

Individual stocks returns are calculated as follows: 


$$
R_{i t}=\frac{\left(P_{t}-P_{t-1}\right)}{P_{t-1}}
$$

where, $P_{t}$ is the closing price of the stock $i$ at time $t$.

To test herding behaviour, the study employ Hwang and Salmon (2004) method in their study on the US and South Korean markets, which is based on the crosssectional volatility of beta coefficients. Hwang and Salmon (2004) method is based on the relationship between the equilibrium beta $\left(\beta_{\text {imt }}\right)$ and its behaviourally biased equivalent $\left(\beta_{i m t}^{b}\right)$ as follows:

$$
\frac{E_{t}^{b}\left(r_{i t}\right)}{E_{t}\left(r_{m t}\right)}=\beta_{i m t}^{b}=\beta_{i m t}-h_{m t}\left(\beta_{i m t}-1\right)
$$

where $E_{t}^{b}\left(r_{i t}\right)$ is the biased expected returns on the asset $\mathrm{i}$ at time $\mathrm{t}$ and $\beta_{i m t}^{b}$ is a measure of systematic risk. $E_{t}\left(r_{m t}\right)$ is the conditional expectation of the market excess returns at time t. $h_{m t}$ is the latent herding behaviour parameter changing over time. When $h_{m t}=0$, this indicates that there is no herding behaviour. When $h_{m t}=1$, this indicates that there is perfect herding behaviour towards market portfolio, that means that all the individual stocks change in accordance with the market portfolio movements. However, When $0<h_{m t}<1$. This indicates the presence of herding behaviour depending on the degree of $h_{m t}$. For measuring herding behaviour on a market wide basis, the cross-sectional variation of $\beta_{i m t}^{b}$ is calculated as follows:

$$
\operatorname{Std}_{c}\left(\beta_{i m t}^{b}\right)=\operatorname{Std}_{c}\left(\beta_{i m t}\right)\left(1-h_{m t}\right)
$$

and when Taking logarithms on both sides of equation (4) we get:

$$
\log \left[\operatorname{Std}_{c}\left(\beta_{i m t}^{b}\right)\right]=\log \left[\operatorname{Std}_{c}\left(\beta_{i m t}\right)\right]+\log \left(1-h_{m t}\right)
$$

Equation (7) may be rewritten as:

$$
\log \left[\operatorname{Std}_{c}\left(\beta_{i m t}^{b}\right)\right]=\mu_{m}+H_{m t}+v_{m t}
$$

where

$$
\log \left[\operatorname{Std}_{c}\left(\beta_{i m t}\right)\right]=\mu_{m}+v_{m t}
$$

with

$$
\begin{aligned}
& \mu_{m}=E\left[\log \left[\operatorname{Std}_{c}\left(\beta_{i m t}\right)\right]\right] \text { and } v_{m t} \sim \operatorname{iid}\left(0, \sigma_{m, v}^{2}\right) \\
& H_{m t}=\log \left(1-h_{m t}\right)
\end{aligned}
$$


Hwang and Salmon (2004) suggest that $H_{m t}$ follows an AR (1) process, which will be estimated using the Kalman filter:

$$
\begin{aligned}
& \log \left[\operatorname{Std}_{c}\left(\beta_{i m t}^{b}\right)\right]=\mu_{m}+H_{m t}+v_{m t} \\
& H_{m t}=\varphi_{m} H_{m, t-1}+\eta_{m t}
\end{aligned}
$$

where $\eta_{m t} \sim \operatorname{iid}\left(0, \sigma_{m, \eta}^{2}\right)$.

The Log $\left[\operatorname{Std}_{c}\left(\beta_{i m t}^{b}\right)\right]$ is expected to change with herding. A significant value of the variance of the error term $\eta_{m t}\left(\sigma_{m, \eta}^{2}\right)$ refers to the existence of herding behaviour and a significant of the persistence parameter $\left(\varphi_{m}\right)$ supports this observation. Furthermore, the $\varphi$ must be stationary, i.e., $|\varphi| \leq 1$.

The cross-sectional standard deviation of betas for each month is calculated by following equation:

$$
\left.\operatorname{Std}_{c}(\beta)_{t}\right)=\sqrt{\frac{\sum_{i-1}^{n}\left(\beta_{i t}-\overline{\beta_{t}}\right.}{n-1}}
$$

In order to construct the herding factor $\left(h_{m t}\right)$, we followed the same methodology used by Fama and French (1993) when creating a portfolio of size and value, where we will construct a portfolio called (herding portfolio), which created by the difference between the returns on the portfolio in which the herd behaviour is presence and statistically significant, it will be symbolized $\left(R h m t_{1}\right)$, and the returns on the portfolio in which the herd behaviour is absence and not statistically significant, it will be symbolized $\left(R h m t_{0}\right)$, as follows:

$$
h_{m t}=R h m t_{1}-R h m t_{0}
$$

\subsection{Model}

The CAMP indicates that the systematic risk is the only one factor which explains the return of any asset, which measured by beta $(B)$. We will add an additional risk factor to the CAPM model, called herding factor $\left(h_{m t}\right)$. To estimate the model parameters, the two pass cross sectional regression was used. The first step is to use the time series regression of the excess return of the stocks on excess market return, and herding factor to estimate beta, which reflects the sensitivity of the stocks return to the change in both the market return and the return of the proposed herd portfolio, by using the following model:

$$
R_{i t}-R_{f}=\alpha+\beta_{m t}\left(R_{m t}-R_{f}\right)+\beta_{h m t}\left[h_{m t}\right]+\varepsilon_{i t}
$$


where $R_{i t}$ and $R_{m t}$ is the rate of return on asset $i$ and market portfolio at time $t$, respectively. $\beta_{m t}, \beta_{h m t}$ are the coefficients (betas) of the independent variables ( $\beta_{m t}$ is the beta of stock $\mathrm{i}$ and $\beta_{h m t}$ is beta of herding behaviour of stock $\left.\mathrm{i}\right), h_{m t}$ is the expected return on herding factor (is proxy for herding behaviour), $R_{f}$ is the riskfree rate at time $t, \varepsilon_{\mathrm{it}}$ is the error term, and $\alpha$ is the intercept.

The second step is to run the cross sectional regression, as follows:

$$
r_{i}=\gamma_{0}+\gamma_{1} b_{i}+\gamma_{2} \beta_{i}+\varepsilon_{i t}
$$

where $r_{i}$ is the average excess return for the stock i over our full sample period, $\gamma 0, \gamma_{1}$ and $\gamma_{2}$ are the parameters that will be estimated, $b i$ is the estimated coefficients of the expected excess return of the market portfolio and $B_{i}$ is the estimated coefficients of the herding factor.

\section{Empirical Results}

\subsection{Testing Herd Behaviour}

In order to construct the herding factor $\left(h_{m t}\right)$, we divided the sample of stocks into two different portfolios, and then we tested the herding in each of them; table (1) and table (2) show the Statistical tests of the tow portfolio:

Table 1 The Statistical Tests of the Portfolio in which the Herd Behaviour is Statistically Significant

\begin{tabular}{ccccccc}
\hline & Coefficient & Std. Error & z-Stat. & Prob. & Variable & Estimate \\
\hline \hline $\mathrm{C}(1) \mu \mathrm{m}$ & $-0,001063$ & 0,089924 & $-0,011821$ & 0,9906 & $\mu \mathrm{m}$ & $-0,001063$ \\
\hline $\mathrm{C}(2) \mathrm{vmt}$ & $-3,140787$ & 0,348612 & $-9,009405$ & 0,0000 & $\sigma_{\mathrm{mv}}$ & 0,207963 \\
\hline $\mathrm{C}(3) \varphi \mathrm{m}$ & 0,867566 & 0,194713 & 4,455622 & 0,0000 & $\varphi \mathrm{m}$ & 0,86757 \\
\hline $\mathrm{C}(4) \mathrm{nt}$ & $-5,541811$ & 1,936191 & $-2,862223$ & 0,0042 & $\sigma_{\mathrm{mn}}$ & 0,062605 \\
\hline
\end{tabular}

Source: Author's construction

Table 1 shows Herding space-state model for 18 stocks of the sample. Coefficient $c(1)$ represent $(\mu \mathrm{m})$ of equation (1), and it is not significant at level of $5 \%$. Coefficient $c(2)$ refers to the error term of equation (1), to avoid negative values of the error term vmt we write it in an exponential form in the space-state model, . The Coefficient $c(3)$ and $c(4)$ represents the persistence parameter $\left(\varphi_{m}\right)$ and the standard deviation $\left(\sigma_{\mathrm{m} n}\right)$ of the state-equation error $\left(\eta_{\mathrm{mt}}\right)$, respectively, And both of them are statistically significant, which confirms the presence of herd behaviour. 
Table 2 shows Herding space-state model for 32 stocks of the sample. The results show that the Coefficient $\mathrm{c}(3)$ and $\mathrm{c}(4)$ represents the persistence parameter $\left(\varphi_{\mathrm{m}}\right)$ and the standard deviation $\left(\sigma_{\mathrm{mn}}\right)$ of the state-equation error $\left(\eta_{\mathrm{mt}}\right)$, respectively are not statistically significant, which confirms the absence of herd behaviour.

Table 2 Statistical Tests of the Portfolio in which the Herd Behaviour is not Statistically Significant

\begin{tabular}{lrrrrrr}
\hline & Coefficient & Std. Error & z-Statistic & Prob. & Variable & Estimate \\
\hline \hline $\mathrm{C}(1) \mu \mathrm{m}$ & -0.147764 & 0.019455 & -7.595299 & 0.0000 & $\mu \mathrm{m}$ & -0.147764 \\
\hline $\mathrm{C}(2) \mathrm{vmt}$ & -21.7119 & $1.48 \mathrm{E}+10$ & $-1.47 \mathrm{E}-09$ & 1.0000 & $\sigma_{\mathrm{mv}}$ & $1.93 \mathrm{E}-05$ \\
\hline $\mathrm{C}(3) \varphi \mathrm{m}$ & 0.023413 & 8.687411 & 0.002695 & 0.9978 & $\varphi \mathrm{m}$ & 0.023413 \\
\hline $\mathrm{C}(4) \mathrm{\eta mt}$ & -4.21498 & 373.3079 & -0.011291 & 0.9910 & $\sigma_{\mathrm{mn}}$ & 0.121543 \\
\hline
\end{tabular}

Source: Author's construction

\subsection{Testing the Capital Asset Pricing Model}

Table 3 shows the Regression results of the CAPM in the EGX from January 2014 to December 2018.

Table 3 Regression Results of the CAPM

\begin{tabular}{|c|c|c|c|c|c|c|c|}
\hline Model & $\begin{array}{l}\text { Sum of } \\
\text { Squares }\end{array}$ & df & $\begin{array}{l}\text { Mean } \\
\text { Square }\end{array}$ & $\mathbf{F}$ & Sig. & $\mathbf{R}^{2}$ & Adj. $R^{2}$ \\
\hline Regression & 0.000 & 1 & 0 & 1.441 & 0.236 & 0.170 & 0.009 \\
\hline Residual & 0.008 & 48 & 0 & & & & \\
\hline Total & 0.008 & 49 & & & & & \\
\hline \multicolumn{8}{|c|}{ Coefficients } \\
\hline & & \multicolumn{2}{|c|}{$\begin{array}{c}\text { Unstandardized } \\
\text { Coefficients }\end{array}$} & $\begin{array}{r}\text { Standardized } \\
\text { Coefficients }\end{array}$ & \multirow{2}{*}{$\mathbf{t}$} & \multirow{2}{*}{\multicolumn{2}{|c|}{ Sig. }} \\
\hline & & B & $\begin{array}{l}\text { Std. } \\
\text { Error }\end{array}$ & Beta & & & \\
\hline (Constant) & & -0.087 & 0.007 & 0.171 & -12.16 & 0.000 & \\
\hline $\mathrm{Rm}-\mathrm{Rf}$ & & 0.01 & 0.007 & & 1.201 & 0.236 & \\
\hline
\end{tabular}

Source: Author's construction

Results show that adjusted $\mathrm{R}$ squared equals 0.009 , which indicates that the explanatory power of beta very weak. The intercept is negative and significant; when the intercept is negative, the returns on stocks are lower than it should have given its risk level; therefore there is a mispricing in the specifications of the 
model, where the intercept (a) should be equal to zero. The slope of the market premium (beta) is not significant and positive, where a t-statistics equal $(0.236)$, therefore the market risk premium is not a determinant of required rate of return. These results do not support the CAPM; which indicate that it does not have the ability to explain excess stock returns in the EGX.

\subsection{Testing the Impact of Herding on the Expected Return}

Table 4 shows the regression results after adding an additional risk factor reflecting herding to the CAPM.

Table 4 Regression Results of the CAMP after Adding the Herding Factor

\begin{tabular}{|c|c|c|c|c|c|c|}
\hline Model & $\begin{array}{l}\text { Sum of } \\
\text { Squares }\end{array}$ & df & $\begin{array}{l}\text { Mean } \\
\text { Square }\end{array}$ & $\mathbf{F}$ & Sig. & Adj. $R^{2}$ \\
\hline Regression & 0.000 & 2 & 0 & \multirow{3}{*}{0.547} & \multirow{3}{*}{0.583} & \multirow{3}{*}{-0.019} \\
\hline Residual & 0.008 & 47 & 0 & & & \\
\hline Total & 0.008 & 49 & & & & \\
\hline \multicolumn{7}{|c|}{ Coefficients } \\
\hline & & \multicolumn{2}{|c|}{$\begin{array}{l}\text { Unstandardized } \\
\text { Coefficients }\end{array}$} & $\begin{array}{l}\text { Standardized } \\
\text { Coefficients }\end{array}$ & \multirow{2}{*}{$\mathbf{t}$} & \multirow{2}{*}{ Sig. } \\
\hline & & B & Std. Error & Beta & & \\
\hline \multicolumn{2}{|c|}{ (Constant) } & -0.08 & 0.003 & & -24.24 & 0 \\
\hline \multicolumn{2}{|c|}{$\mathrm{Rm}-\mathrm{Rf}$} & 0.00 & 0.003 & 0.137 & 0.43 & 0.669 \\
\hline \multicolumn{2}{|c|}{$\mathrm{hmt}$} & 0.00 & 0.002 & 0.016 & 0.049 & 0.961 \\
\hline
\end{tabular}

Source: Author's construction

Results show that Adjusted R Square equal -0.019 , which indicates that the explanatory power of the risk coefficients in the model is very weak. The intercept is significant and negative; while the intercept should be equal to zero. The slope of the market premium (beta) is not significant and equal to zero with a t-statistics equal (0.669), so the market risk premium is not a determinant of required rate of return. The $\left(h_{m t}\right)$ coefficient is insignificant and equal to zero with a t-statistics equal (0.961), therefore the results do not support the CAPM after adding the herding factor, therefore there is no effect of herding behaviour on the expected return in the EGX. 


\section{Conclusions}

The study examined the impact of herding behaviour on the expected return in the EGX by adding an additional risk factor reflecting herding behaviour to the CAPM, we used a sample consist of 50 stocks listed on the EGX from January 2014 to December 2018. At the first, we investigated the validity of the CAPM by using the two pass cross sectional regression. And then we re-tested the CAPM model after adding the additional risk factor, in order to know the effect of herding on the expected return in the EGX.

In order to construct the herding factor, we followed the same methodology used by Fama and French (1993) when creating a portfolio of size and value, where we will construct a portfolio called herding portfolio, which created by the difference between the returns on the portfolio in which the herd behaviour is presence and statistically significant, it consists from 18 stocks. The returns on the portfolio in which the herd behaviour is absence and is not statistically significant, it consists 32 stocks. We used the same methodology developed by Hwang and Salmon (2004), where they estimated the state space model using Kalman filter methodology to measure herd behavior. Based on our statistical results, we found that the CAPM does not have the ability to explain excess stock returns in its original form and after adding the herding factor as additional risk factor, therefore there is no effect of herding behaviour on the expected return in the EGX.

Based on our statistical results, we found that the CAPM does not have the ability to explain excess stock returns in its original form and after adding the herding factor as additional risk factor, therefore the beta coefficient is not appropriate in evaluating the relationship between risk and return and there is no effect of herding behaviour on the expected return in the Egyptian Stock Exchange.

Our research could be interesting to both researchers and investors. Researchers may re-test the proposed model in different financial markets, where they may obtain better results on explaining the relationship between return and risk. On the other hand, it can be beneficial to investors who are concerned to know anomalies that could affect the returns of their investments.

\section{References}

Acharya, V. V. and Pedersen, L. H. (2005). Asset Pricing with Liquidity Risk. Journal of Financial Economics, 77(2), pp. 375-410.

Bawa, V. and Lindenberg, E. (1977). Capital Market Equilibrium in a mean, Lower Partial Moment Framework. Journal of Financial Economics, 5(2), pp. 189-200.

Bikhchandani S. and Sharma S. (2001). Herd Behaviour in Financial Markets. IMF Staff Papers, 47(3), Internatinal Monetary Fund. 
Black, F. (1972). Capital Market Equilibrium with Restricted Borrowing. The Journal of Business, 45(3), pp. 444-455.

Brock, W. A. (1979). Asset Prices in a Production Economy. Social Science Working Paper 275, California Institute of Technology.

Chang, E. C., Cheng, J. W. and Khorana, A. (2000). An Examination of Herd Behavior in Equity Markets: An International Perspective. Journal of Banking and Finance, 24(10), pp.1651-1679.

Choudhary, K. and Choudary, S. (2010). Testing Capital Asset Pricing Model: Empirical Evidences from India Equity Market. Eurasian Journal of Business and Economics, 3(6), pp. 127-138.

Christie, W. G., Huang, R. D. (1995). Following the Pied Piper: Do Individual Returns Herd Around the Market? Financial Analysts Journal, 51(4), pp. 31-37.

Clare, A. D., Priestley, R. and Thomas, S.H. (1998). Reports of Beta's Death Are Premature: Evidence from the UK. Journal of Banking and Finance, 22, pp. 12071229.

Devenow, A. and Welch, I. (1996). Rational Herding in Financial Economics. European Economic Review, 40(3-5), 603-615.

Elkhaldi, A. and Benabdelfatteh, Y. (2014). Testing Herding Effects on Financial Assets Pricing: The Case of the Tunisian Stock Market. British Journal of Economics, Management and Trade, 4(7), pp. 1046-1059.

Fama, E. F. and French, K. R. (1993). Common Risk Factors in the Returns on Bonds and Stocks. Journal of Financial Economics, 33, 3-56.

Hogan, W., Warren, J. (1974). Toward the Development of an Equilibrium Capital Market Model Based on Semivariance. Journal of Financial and Quantitative Analysis, 9(1), pp. 1-11.

Hwang, S. and Salmon, M. (2004). Market Stress and Herding. Journal of Empirical Finance, 11(4), pp. 585-616.

Javaira, Z. Hassan, A. (2015). An Examination of Herding Behavior in Pakistani Stock Market. International Journal of Emerging Markets, 10(3), pp. 474-490.

Lee, Y. H., Liao, T. H., and Hsu, C. M. (2015). The Impact of Macroeconomic Factors on the Herding Behaviour of Investors. Asian Economic and Financial Review, 5(2), pp. 295-304.

Lintner, J. (1965). The Valuation of Risk Assets and Selection of Risky Investments in Stock Portfolios and Capital Budgets. Review of Economics and Statistics, 47(1) 47, pp. 13-37. 
Lucas, R. (1978). Asset Prices in an Exchange Economy. Econometrica, 46(6), pp. 1429-1445.

Markowitz, H. (1952). Portfolio Selection. The Journal of Finance, 7(1), pp. 77-91. Mayers, D. (1972). Nonmarketable Assets and Capital Market Equilibrium Under Uncertainty. In: Studies in the Theory of Capital Markets (edited by M. C. Jensen), pp. 223-248.

Merton, R. K. (1973). The Sociology of Science: Theoretical and Empirical Investigations. University of Chicago press.

Messis, P. and Zapranis, A. (2014). Herding Behaviour and Volatility in the Athens Stock Exchange. The Journal of Risk Finance, 15(5), pp. 572-590.

Metwally, A. H., Eldomiaty, T. and Abdel-Wahab, L. A. (2016). Does Herding Behaviour Vary in Bull and Bear Markets? Perspectives from Egypt. International Journal of Behavioural Accounting and Finance, 6(1), pp. 26-53.

Ouarda, M., El Bouri, A. and Bernard, O. (2012). Herding Behavior under Markets Condition: Empirical Evidence on the European Financial Markets. International Journal of Economics and Financial Issues, 3(1), pp. 214-228.

Özsu, H. H. (2015). Empirical Analysis of Herd Behavior in Borsa Istanbul. International Journal of Economic Sciences, 4(4), pp. 27-52.

Ross, S. A. (1976). The Arbitrage Theory of Capital Asset Pricing. Journal of Economic Theory, 13(3), pp. 341-360.

Sharpe, W. F. (1964). Capital Asset Prices: A Theory of Market Equilibrium under Conditions of Risk. Journal of Finance, 19(3), pp. 425-442.

Solnik, B. H. (1974). An Equilibrium Model of the International Capital Market. Journal of Economic Theory, 8(4), pp. 500-524.

Strong, N. and Xu, X. G. (1997). Explaining the Cross-section of UK Expected Stock Returns. British Accounting Review, 29(1), pp. 1-23.

Theriou, N. G., Maditinos, D. I., Chadzoglou, P. and Anggelidis, V. (2005). The Cross-section of Expected Stock Returns: An Empirical Study in the Athens Stock Exchange. Managerial Finance, 31(12), pp. 58-78.

Vieira, E. F. S. and Pereira, M. S. V. (2015). Herding Behaviour and Sentiment: Evidence in a Small European Market. Revista de Contabilidad, 18(1), pp. 78-86. 